\title{
N-methyl pyrrolidone promotes ankle fracture healing by inhibiting inflammation via suppression of the mitogen-activated protein kinase signaling pathway
}

\author{
JUN BIAN $^{1 *}$, DAN CAO $^{1 *}$, JIE SHEN $^{1 *}$, BO JIANG $^{1}$, DAN CHEN $^{1}$ and LANZHENG BIAN ${ }^{2}$ \\ Departments of ${ }^{1}$ Orthopedic and ${ }^{2}$ Surgery, Children's Hospital of Nanjing Medical University, \\ Nanjing, Jiangsu 210009, P.R. China
}

Received November 19, 2016; Accepted November 15, 2017

DOI: $10.3892 /$ etm.2018.5842

\begin{abstract}
N-methyl pyrrolidone (NMP), a small bioactive molecule, has the potential to stimulate bone formation and inhibit osteoclast differentiation. The aim of the present study was to investigate the effect of NMP on the inflammatory response and underlying molecular mechanisms in MG-63 cells. The mRNA and protein expression of cytokines from peripheral blood in children with or without ankle fracture were determined by reverse transcription-quantitative polymerase chain reaction (RT-qPCR) and ELISA, respectively. MG-63 cells were pre-treated with/without NMP and stimulated with $1 \mu \mathrm{M}$ bradykinin (BK). The production of cytokines from MG-63 cells was assessed by western blotting and RT-qPCR. The expression of inducible nitric oxide synthase (iNOS) and cyclooxygenase-2 (COX-2) mRNA and protein were measured using western blotting and/or RT-qPCR. Western blotting was used to examine the activation level of mitogen activated protein kinase. Compared with healthy children, levels of tumor necrosis factor (TNF- $\alpha$ ), interleukin (IL)-1 $\beta$ and IL-6 mRNA and protein were upregulated in children with ankle fracture. NMP treatment did not induce cytotoxicity in MG-63 cells. The BK-induced upregulation of TNF- $\alpha$, IL-1 $\beta$, IL-6, iNOS and COX-2 mRNA and protein was reversed in a dose-dependent manner by NMP. Furthermore, NMP downregulated the activation of c-Jun NH2-terminal kinase
\end{abstract}

Correspondence to: Mrs Dan Chen, Department of Orthopedic, Children's Hospital of Nanjing Medical University, 72 Guangzhou Road, Gulou, Nanjing, Jiangsu 210009, P.R. China

E-mail: chendan_etyy@163.com

Mrs Lanzheng Bian, Department of Surgery, Children's Hospital of Nanjing Medical University, 72 Guangzhou Road, Gulou, Nanjing, Jiangsu 210009, P.R. China

E-mail: bianlz_etyy@163.com

${ }^{*}$ Contributed equally

Key words: N-Methyl-2-pyrrolidone, inflammatory factors, mitogen-activated protein kinase signaling pathway and p38 pathways, but not the extracellular signal-related kinase pathway. Therefore, the results of the current study demonstrate that NMP inhibits inflammation dependent on the mitogen-activated protein kinase pathway in MG-63 cells, indicating that it may be beneficial in the healing of fractures.

\section{Introduction}

Fracture is a very common bone injury. The occurrence of fracture in the forearms, hands, and feet of children is high, particularly in the ankles, with a global incident rate of 187 per 100,000 people. However, incidence rates vary among countries, ages, sexes and sites of injury (1-3). Due to the specific characteristics of children's bones, delayed and/or improper treatment of ankle fracture in children may cause bone deformity and disability $(4,5)$. The process of bone formation involves a balance between osteoblast and osteoclast activity and the healing of fractures requires a large number of osteoblasts (6). It has been demonstrated that there is a link between osteoclasts and inflammatory cytokines: High numbers of osteoclasts are associated with high numbers of inflammatory cytokines, including TNF- $\alpha$ and IL-1, following bone fracture (7).

Owing to the close association of chronic inflammatory processes to endogenous prostaglandin production (8), bradykinin (BK) stimulates bone resorption in neonatal mouse calvariae, suggesting that kinins should be regarded as candidates for osteoclastic activation in inflammatory conditions $(9,10)$. BK may stimulate bone resorption and potentiate the bone resorptivity induced by interleukin (IL)-1 (11). Furthermore, receptor activator of nuclear factor $\kappa-\mathrm{B}$ ligand (RANKL), a tumor necrosis factor (TNF)-related cytokine, is an important factor affecting bone resorption $(12,13)$. RANKL may activate the cognate receptor RANK on osteoclast progenitor cells and TNF receptor-associated factors (TRAFs)/mitogen-activated protein kinases, resulting in the differentiation of osteoclast progenitor cells that may then fuse into multinucleated, bone-resorbing osteoclasts (12-14).

N-methyl pyrrolidone (NMP), a small bioactive molecule, enhances bone formation and inhibits osteoclast differentiation $(15,16)$. It has been demonstrated that NMP inhibits inflammation by repressing the NF-kB pathway (17). This indicates that NMP may be used as an adjuvant therapy alongside 
established methods of bone fracture treatment. Therefore, the present study investigated the effects of NMP on inflammatory process using MG-63 cells stimulated with BK as an inflammatory process model. It was demonstrated that NMP reduced the expression of iNOS/COX-2 and the increase in the expression of inflammatory cytokines, including IL-1 $\beta$, IL-6 and TNF- $\alpha$, induced by BK. Taken together, the results of the current study suggest that NMP exerts its anti-inflammatory function by downregulating the expression of phosphorylated (p)-c-Jun N-terminal kinases (JNK) and p-p38, which may regulate osteoblast and osteoclast activity by decreasing and increasing their numbers, respectively. This may promote bone formation and thus help to relieve ankle fractures in children.

\section{Materials and methods}

Patients. A total of 60 peripheral blood samples $(2 \mathrm{ml}$ per individual) from 60 children with ankle fracture, as well as 60 peripheral blood samples from 60 healthy children were collected at Children's Hospital Affiliated to Nanjing Medical University from August 2015 to April 2016. The average age of patients and healthy controls were $6.0 \pm 1.2$ and $5.9 \pm 1.3$ years old, respectively. The ratio of the boys and girls was equal in the two groups of children. Informed consent was obtained from the parents or guardians of all children enrolled and the present study was approved by the Ethics Committee of Children's Hospital Affiliated to Nanjing Medical University (Nanjing, China).

Cell culture. The human osteoblastic osteosarcoma cell line MG-63, which expresses osteoblastic phenotypes, was obtained from the American Type Culture Collection (cat. no. CRL-1427; Manassas, VA, USA) and was used in current study. Cells were seeded into $9.5 \mathrm{~cm}^{2}$ culture dishes at a concentration of $10^{4}$ cells $/ \mathrm{cm}^{2}$ and $\alpha$-Minimum Essential medium (MEM) $/ 10 \%$ fetal calf serum (FCS; Gibco; Thermo Fisher Scientific, Inc., Waltham, MA, USA) was added to each dish. Cells were cultured for 1-2 days until they reached $80-90 \%$ confluence, then washed twice with phosphate-buffered saline (PBS) twice and once with serum-free $\alpha$-MEM. Finally, cells were cultured for $48 \mathrm{~h}$ at $37^{\circ} \mathrm{C}$ in $10 \mathrm{nM}$ NMP (Selleck Chemicals, Houston, TX, USA) containing $\alpha$-MEM/1\% FCS. Subsequently, $1 \mu \mathrm{M}$ BK was added and cells were cultured for a further $24 \mathrm{~h}$ at $37^{\circ} \mathrm{C}$. Cells were divided into 4 different groups: A control group (cells without any treatment), a $1 \mu \mathrm{M}$ BK induced group (cells were treated with $1 \mu \mathrm{M} \mathrm{BK}$ for $24 \mathrm{~h}$ at $37^{\circ} \mathrm{C}$ ), a $1 \mu \mathrm{M}$ $\mathrm{BK}+5 \mathrm{mM}$ NMP group (cells were treated with $5 \mathrm{mM}$ NMP for $48 \mathrm{~h}$ at $37^{\circ} \mathrm{C}$ and then $1 \mu \mathrm{M} \mathrm{BK}$ for $24 \mathrm{~h}$ at $37^{\circ} \mathrm{C}$ ) and a $1 \mu \mathrm{M}$ $\mathrm{BK}+10 \mathrm{mM}$ NMP group (cells were treated with $10 \mathrm{mM}$ NMP for $48 \mathrm{~h}$ at $37^{\circ} \mathrm{C}$ and then $1 \mu \mathrm{M} \mathrm{BK}$ for $24 \mathrm{~h}$ at $37^{\circ} \mathrm{C}$ ).

Cell viability assay. Cell viability was tested using a Water-soluble tetrazolium-1 (WST-1) Cell Proliferation and Cytotoxicity assay kit (cat. no. C0036; Beyotime Institute of Biotechnology, Haimen, China), a colorimetric assay for nonradioactive quantification of cellular proliferation, viability and cytotoxicity, according to the manufacturer's protocol. Briefly, MG-63 cells were cultured in 96-well plates for $24 \mathrm{~h}$ and then incubated with different concentrations of $\operatorname{NMP}(0,5$ or $10 \mathrm{mM}$ ) (17) for $48 \mathrm{~h}$ at $37^{\circ} \mathrm{C}$. Following stimulation, WST-1
(1/10 of total volume) was added to each well and incubated for a further $2 \mathrm{~h}$ at $37^{\circ} \mathrm{C}$ in the dark. Absorbance at $450 \mathrm{~nm}$ in each well was evaluated using a microplate reader.

ELISA assay. The supernatants were collected from the peripheral blood of healthy controls and patients with ankle fracture via centrifugation $\left(3,000 \mathrm{x}\right.$ g at $4^{\circ} \mathrm{C}$ for $\left.15 \mathrm{~min}\right)$. ELISA kits were then used to detect TNF- $\alpha$ (cat. no. E-EL-H0109c), IL-1 $\beta$ (cat. no. E-EL-H0149c) and IL-6 (cat. no. E-EL-H0102c) levels in the peripheral blood of healthy controls and patients with ankle fracture following the manufacturer's protocol. All ELISA kits were purchased from Elabscience Biotechnology Co., Ltd (Wuhan, Hubei, China).

Reverse transcription-quantitative polymerase chain reaction $(R T-q P C R)$. Total RNA from MG-63 cells was isolated using TRIzol (Invitrogen; Thermo Fisher Scientific Inc.), following the manufacturer's protocol. A total of $1 \mu \mathrm{g}$ RNA was reverse transcribed into cDNA using the TaqMan microRNA Reverse Transcription kit (Invitrogen) according to the manufacturer's protocol. Analysis of mRNA levels was performed using the TaqMan ${ }^{\circledR}$ Universal PCR Master Mix kit (Thermo Fisher Scientific Inc.) on an ABI PRISM 7900 HT sequence-detection system (Applied Biosystems; Thermo Fisher Scientific, Inc.). The thermocycling conditions were as follows: $95^{\circ} \mathrm{C}$ for $10 \mathrm{~min}$, followed by 40 cycles of $95^{\circ} \mathrm{C}$ for $10 \mathrm{sec}$ and $60^{\circ} \mathrm{C}$ for $60 \mathrm{sec}$. The primer sequences used were as follows: IL-1 $\beta$, forward, 5'-TGTGAAATGCCACCTTTTGA-3' and reverse, 5'-TGAGTGATACTGCCTGCCTG-3'; IL-6, forward, 5'-CCG GAGAGGAGACTTCACAG-3' and reverse, 5'-CAGAATTGC CATTGCACA-3'; TNF- $\alpha$, forward, 5'-GAACTGGCAGAA GAGGCACT-3' and reverse, 5'-GGTCTGGGCCATAGAACT GA-3'; cyclooxygenase (COX)-2, forward, 5'-TCCATTGAC CAGAGCAGAGA-3' and reverse, 5'-TCTGGACGAGGTTTT TCCAC-3'; inducible nitric oxide synthase (iNOS), forward, 5'-CACCTTGGAGTTCACCCAGT-3' and reverse, 5'-ACC ACTCGTACTTGGGATGC-3', GAPDH, forward, 5'-GGC ATTGCTCTCAATGACAA-3' and reverse, 5'-TGTGAGGGA GATGCTCAGTG-3'. Relative gene expression was quantified using the $2^{-\Delta \Delta \mathrm{Cq}}$ method (18).

Western blotting. MG-63 cells were cultured to $80-90 \%$ confluence monolayers in $60 \mathrm{~cm}^{2}$ petri dishes, washed twice in PBS and once in serum free $\alpha$-MEM, then cultured with $\alpha-M E M$ (without serum) for $24 \mathrm{~h}$.

Following incubation, MG-63 cells were washed with PBS three times prior to addition of the lysis buffer (Beijing Solarbio Science \& Technology Co., Ltd., Beijing, China). Protein concentrations of the cell lysates were measured using a BCA assay (Thermo Fisher Scientific, Inc.), with bovine serum albumin (Thermo Fisher Scientific, Inc.) acting as a standard. The sample buffer was added to cell lysates and boiled for 3 min. Samples (2 $\mu \mathrm{g}$ /lane) were loaded on 10\% SDS-PAGE and blotted onto PVDF membranes, which were blocked with $5 \%$ skim milk for $2 \mathrm{~h}$ at room temperature. Membranes were subsequently incubated with primary antibodies (all Cell Signaling Technology Inc., Danvers, MA, USA) against TNF- $\alpha$ (1:1,000; cat. no. 3707), IL-1 $\beta$ (1:1,000; cat. no. 12703), IL-6 (1:1,000; cat. no. 12153), p-p38 (1:1,000; cat. no. 1170), p-ERK (1:1,000; cat. no. 4370), p-JNK (1:1,000; cat. no. 4668), 

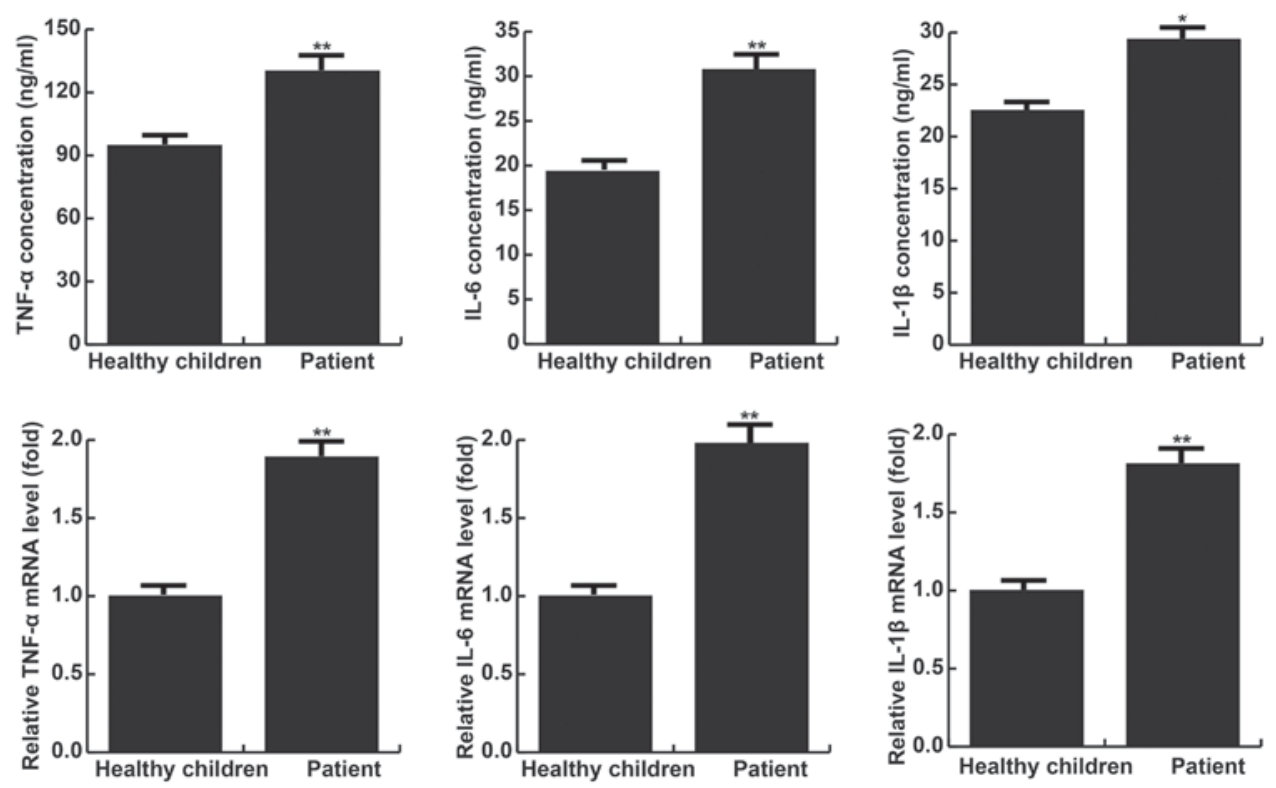

Figure 1. In children with ankle fracture, TNF- $\alpha$, IL-1 $\beta$ and IL-6 levels are higher than in healthy children. In children with ankle fracture, levels of TNF- $\alpha$, IL-1 $\beta$ and IL- 6 mRNA and protein were significantly increased compared with healthy children. Results are presented as the mean \pm standard deviation. ${ }^{*} \mathrm{P}<0.05$ and ${ }^{* *} \mathrm{P}<0.01$ vs. healthy children. TNF- $\alpha$, tumor necrosis factor $\alpha$; IL-1 $\beta$, interleukin $1 \beta$; IL-6, interleukin 6.

and $\beta$-actin (1:5,000; cat no. 4970) overnight at $4^{\circ} \mathrm{C}$, washed 3 times for $10 \mathrm{~min} /$ wash in TBST and then incubated with the anti-rabbit immunoglobulin $\mathrm{G}$, horseradish peroxidase-linked Antibody (1:5,000; cat. no. 7074; Cell Signaling Technology Inc.), for $1 \mathrm{~h}$ at room temperature. Membranes were then washed with TBST and developed using a chemiluminence detection kit (cat. no. 6883; Cell Signaling Technology Inc.), in accordance with the manufacturer's protocol.

Statistical analysis. All experiments were performed $\geq 3$ times and results were expressed as the mean \pm standard deviation. Comparisons between two groups were analyzed using the Student's t-test and comparisons among multiple groups were assessed using one-way analysis of variance followed by the Bonferroni post-hoc test. $\mathrm{P}<0.05$ was determined to indicate a statistically significant difference.

\section{Results}

TNF- $\alpha, I L-1 \beta$ and IL- 6 levels are higher in children with fractured ankles than in healthy children. The results of RT-qPCR indicated that levels of TNF- $\alpha$, IL- $1 \beta$ and IL- 6 mRNA were significantly increased in children with ankle fractures compared with healthy children (all $\mathrm{P}<0.05$; Fig. 1). Furthermore, levels TNF- $\alpha$, IL- $1 \beta$ and IL- 6 protein were measured using ELISA and it was determined that they were significantly increased in patients with ankle fractures compared with healthy children (all $\mathrm{P}<0.01$; Fig. 1).

MG-63 cells treated with NMP do not exhibit cytotoxicity. Cells were divided into 3 different groups: A control group, a $5 \mathrm{nM}$ NMP treatment group and a $10 \mathrm{mM}$ NMP treatment group. Cell viability in each group was analyzed. The results demonstrated that there were no significant changes in absorbance among the 3 different groups (Fig. 2), indicating that NMP does not induce cytotoxicity in MG-63 cells.

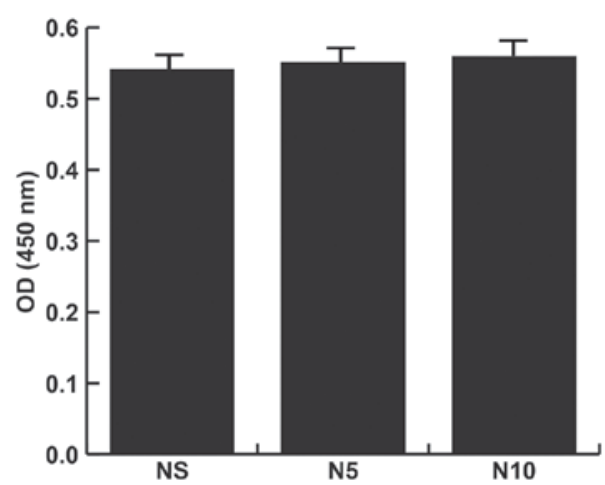

Figure 2. NMP induces no cytotoxicity in MG-63 cells. There were no significant changes in cell viability among the 3 groups. Results are presented as the mean \pm standard deviation. NS, control group; N5, 5 mM NMP treatment group; N10, 10 mM NMP treatment group; NMP, N-methyl pyrrolidone; OD, optical density.

NMP significantly inhibits the BK-induced increase of $C O X-2$ and $i N O S$. Cells were divided into 4 different groups: A control group, a $1 \mu \mathrm{M} \mathrm{BK}$ induced group, a $1 \mu \mathrm{M} \mathrm{BK}+5 \mathrm{mM}$ NMP group and a $1 \mu \mathrm{M} \mathrm{BK}+10 \mathrm{mM}$ NMP group. The results indicated that, compared with the control group, levels of COX-2 and iNOS mRNA were significantly increased in the BK group $(\mathrm{P}<0.01)$. This increase in COX-2 and iNOS levels was significantly reversed following treatment with $5 \mathrm{mM}$ $(\mathrm{P}<0.05)$ and $10 \mathrm{mM}$ NMP $(\mathrm{P}<0.01$; Fig. 3$)$. Levels of COX-2 and iNOS proteins were also assessed using western blotting and the results were consistent with those of RT-qPCR (Fig. 3).

NMP treatment significantly inhibits the BK-induced increase of TNF- $\alpha, I L-1 \beta$ and $I L-6$. In the BK group, levels of TNF- $\alpha$, IL-1 $\beta$ and IL- 6 mRNA were significantly higher compared with the control group $(\mathrm{P}<0.01)$; however, these increases were attenuated following treatment with $10 \mathrm{nM}$ NMP $(\mathrm{P}<0.05$; 

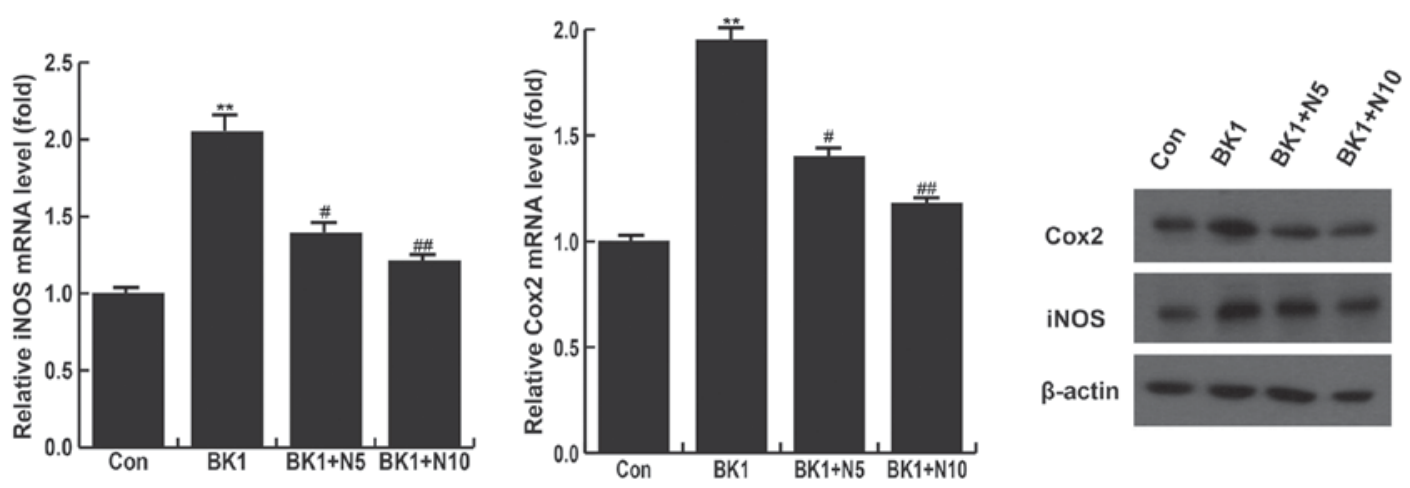

Figure 3. NMP significantly inhibits the BK-induced increase of COX-2 and iNOS mRNA expression. BK stimulation significantly increased levels of COX-2 and iNOS mRNA and this increase was reversed following treatment with NMP. Levels of COX-2 and iNOS proteins were similar to those of mRNA. ${ }^{* *} \mathrm{P}<0.01$ vs. Con; ${ }^{\#} \mathrm{P}<0.05$ and ${ }^{\# \#} \mathrm{P}<0.01$ vs. BK1. Con, control group; BK1, $1 \mu \mathrm{M}$ BK treatment group; BK1 + N5, $1 \mu \mathrm{M}$ BK +5 mM NMP treatment group; BK1 + N10, $1 \mu \mathrm{M}$ BK +10 mM NMP treatment group; BK, bradykinin; NMP, N-methyl pyrrolidone; COX-2, cyclooxygenase-2; iNOS, inducible nitric oxide synthase.
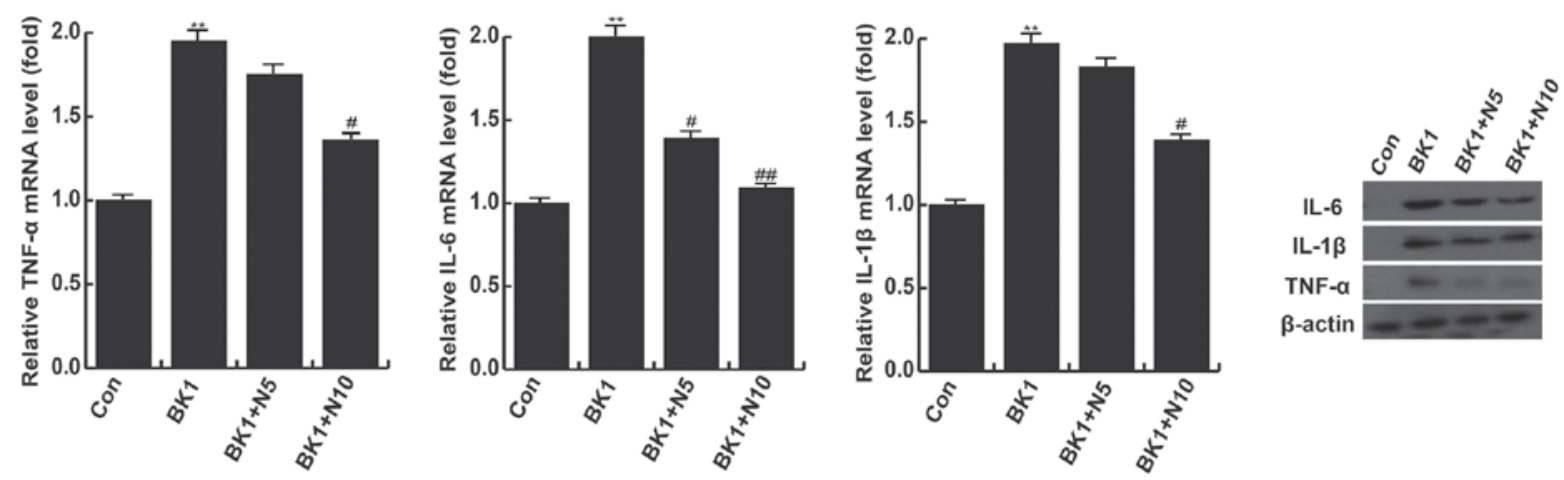

Figure 4. NMP significantly inhibits the BK-induced increase of TNF- $\alpha$, IL-1 $\beta$ and IL-6. Following stimulation with BK, levels of TNF- $\alpha$, IL-1 $\beta$ and IL-6 mRNA were significantly higher compared with the control group. mRNA expression of TNF- $\alpha$, IL-1 $\beta$ and IL- 6 were inhibited following treatment with NMP. Changes in the expression of TNF- $\alpha$, IL- $1 \beta$ and IL-6 protein were similar to those of mRNA. ${ }^{* *} \mathrm{P}<0.01$ vs. Con; ${ }^{*} \mathrm{P}<0.05$ and ${ }^{\# \#} \mathrm{P}<0.01$ vs. BK1. Con, control group; BK1, $1 \mu \mathrm{M}$ BK treatment group; BK1 + N5, $1 \mu \mathrm{M} \mathrm{BK}+5$ mM NMP treatment group; BK1 + N10, $1 \mu \mathrm{M}$ BK $+10 \mathrm{mM}$ NMP treatment group $\mathrm{BK}$, bradykinin; NMP, N-methyl pyrrolidone; TNF- $\alpha$, tumor necrosis factor $\alpha$; IL-1 $\beta$, interleukin 1 $\beta$; IL-6, interleukin 6.

Fig. 4). Treatment with $5 \mathrm{nMNMP}$ did not significantly reverse the increase in TNF- $\alpha$ and IL-1 $\beta$ mRNA expression but did significantly reverse the increase in IL-6 mRNA expression induced by $\mathrm{BK}(\mathrm{P}<0.05$; Fig. 4). The results of western blotting demonstrated that changes in the levels of TNF- $\alpha$, IL-1 $\beta$ and IL-6 protein were in line with the changes in mRNA levels (Fig. 4).

NMP markedly inhibits the BK-induced overactivation of JNK and $p 38$. Compared with the control group, the expression of phosphorylated (p)-extracellular signal-regulated kinase (ERK), p-JNK and p-p38 were all markedly upregulated in the BK group. Treatment with $10 \mathrm{nM}$ NMP markedly inhibited the BK-induced upregulation of p-JNK and p-p38 expression. However, it did not decrease the expression of p-ERK (Fig. 5).

\section{Discussion}

Taken together, the results of the present study indicate that, compared with healthy children, levels of TNF- $\alpha$, IL- $1 \beta$ and IL-6 were upregulated in children with ankle fracture. NMP dose-dependently reversed the BK-induced upregulation of TNF- $\alpha$, IL- $1 \beta$, IL- 6 , iNOS and COX-2 mRNA and protein, and also inhibited the BK-induced activation of JNK and p38 pathways in MG-63 cells. The anti-inflammatory function of NMP may reduce osteoclast and increase osteoblast levels, thus promoting bone formation. Therefore, the current study identified a potential novel method of treating ankle fracture.

It has been demonstrated that persistent inflammation directly affects osteogenesis in trauma-induced fracture; however, the precise molecular mechanism of action remains unclear and further research into the association between inflammation and osteoblasts/osteoclasts is required (19). A normal physiological inflammatory response is a type of defensive reaction, which is beneficial to fracture healing; however, the long-term chronic inflammatory response caused by infection (20) or other elements, including diabetes mellitus, smoking and alcohol, (21) inhibits fracture healing. It has been reported that TNF- $\alpha$ expression is significantly higher in the blood of patients with rheumatoid arthritis (22). Furthermore, multiple inflammatory factors including TNF- $\alpha$, IL-1 $\beta$ and IL- 6 stimulate the differentiation and formation of osteoclasts (23-26). Therefore, the current study investigated whether TNF- $\alpha$, IL- $1 \beta$ and IL- 6 levels differed between healthy children and those with ankle fracture. The results of RT-qPCR and western blotting demonstrated that levels of 


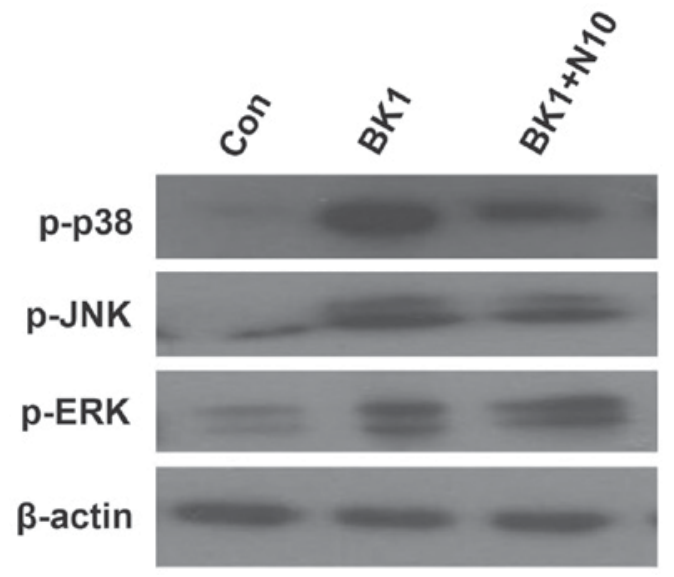

Figure 5. NMP significantly inhibits the BK-induced overactivation of JNK and $\mathrm{p} 38$. BK induced the upregulation of p-ERK, p-JNK and p-p38. NMP treatment markedly inhibited the BK-induced upregulation of p-JNK and p-p38; however, NMP treatment induced no significant effect on p-ERK. Con, control group; BK1, $1 \mu \mathrm{M}$ BK treatment group; BK1 + N5, $1 \mu \mathrm{M} \mathrm{BK}+5 \mathrm{mM}$ NMP treatment group; BK1 + N10, $1 \mu \mathrm{M}$ BK $+10 \mathrm{mM}$ NMP treatment group; p-, phosphorylated; NMP, N-methyl pyrrolidone; BK, bradykinin; JNK, c-Jun NH2-terminal kinase; ERK, extracellular signal-related kinase.

inflammatory factors were all significantly higher in children with ankle fracture than in healthy children. The current study aimed to identify novel effective methods of treating ankle fracture.

The human osteoblastic osteosarcoma cell line MG-63 was used in the present study. BK was reported to stimulate bone resorption in rats (11); thus $1 \mu \mathrm{M}$ BK was used to generate an inflammatory model in the present study. Previous studies demonstrated that NMP enhances bone formation and inhibits osteoclast differentiation $(15,16)$. Therefore, the present study investigated the effects of NMP on the BK-stimulated inflammatory response in MG-63 cells.

The current study investigated whether NMP induced cytotoxicity in MG-63 cells. Cell viability was evaluated and the results demonstrated that NMP did not induce cytotoxicity in MG-63 cells. Therefore, two different concentrations of NMP were used to assess the effect of NMP on BK-induced inflammation in MG-63 cells.

COX-2 is an enzyme encoded by the prostaglandin endoperoxide synthase 2 gene (27). In the majority of cells, COX-2 is not expressed or underexpressed in normal physiological conditions but overexpressed in inflammatory conditions (28).

iNOS is calcium-insensitive and the gene that codes for iNOS is located on chromosome 17 (29). The activation of the $\mathrm{NF}-\kappa \mathrm{B}-$ dependent iNOS promoter supports the inflammation-mediated stimulation of iNOS transcription (30). Furthermore, iNOS produces large quantities of NO following stimulation by IL-1 and TNF- $\alpha(31)$.

It has been reported that BK stimulates the expression of COX-2 mRNA in calvarial bones (32). LPS may also induce the expression of iNOS and COX-2 in RAW264.7 macrophages (17). Therefore, the current study evaluated whether BK induces the upregulation of iNOS and COX-2, and whether NMP significantly reverses BK-induced upregulation in MG-63 cells. Compared with the control group, BK significantly increased levels of COX-2 and iNOS mRNA and protein, which were significantly inhibited by treatment with 10 nM NMP.

A link between osteoclast levels and inflammatory cytokines, including TNF- $\alpha$ and IL-1, has been identified (7). BK stimulates bone resorption and potentiates the bone resorptivity of IL-1 (11). Additionally, RANKL participates in bone resorption $(12,13)$ and activates TRAFs (12-14). Therefore, the current study aimed to identify the effect of NMP on the expression of inflammatory cytokines. The results demonstrated that BK significantly increased levels of TNF- $\alpha$, IL-1 $\beta$ and IL-6 mRNA and protein compared with the control group. These increases were reversed by treatment with $10 \mathrm{nM}$ NMP.

Previous studies have suggested that NMP may enhance bone formation and inhibit osteoclast differentiation $(15,16)$. However, the molecular mechanism by which NMP exerts its anti-inflammatory function in MG-63 cells remains unresolved.

p38 and JNK, but not ERK, are involved in important signal-transducing pathways in the interactions between kinins and IL-1 $\beta$ that lead to the upregulation of COX-2 expression (32). Western blotting was performed to determine the activation levels of ERK, JNK and p38. The results indicated that, compared with the control group, the expression of p-ERK, p-JNK and p-p38 were all significantly upregulated following induction with BK. Furthermore, NMP treatment significantly inhibited the BK-induced upregulation of p-JNK and p-p38, but not p-ERK.

Taken together, these results indicate that NMP represses inflammation in MG-63 cells that is induced following activation of the JNK and p38 pathways. The anti-inflammatory function of NMP may therefore promote the healing of ankle fracture by enhancing bone formation. Thus, it may be utilized in conjugation with other established methods of fracture treatment in the future; however, the clinical effects of NMP on children with ankle fracture remains unclear.

Ankle injury is a common pediatric injury that causes persistent pain, movement limitation, swelling and stiffness (33). Timely diagnosis, treatment and nursing care are very important for the reduction of pain and the healing of fractures. The Ottawa Ankle Rules (OAR) (34-36) that were developed by Ottawa emergency physicians were adopted to assist in determining if radiography should be used to determine whether radiography would be appropriate to diagnose ankle fracture in a patient experiencing ankle pain. It has been demonstrated that when pediatric emergency department (ED) nurses accurately apply and interpret OAR, children in the hospital ED were treated with a nursing collaborative practice protocol (CPP) to minimize throughput time and expedite patient care (37). This suggests that CPP may be a novel treatment in children with fractured ankles and NMP may be used as a part of CPP. However, the clinical application of NMP still requires further research to confirm this proposition. Future studies should be undertaken to investigate the effect of NMP on fractures and novel therapeutic strategies, potentially including CPP, for the treatment of children with ankle fractures. 


\section{References}

1. MacIntyre NJ and Dewan N: Epidemiology of distal radius fractures and factors predicting risk and prognosis. J Hand Ther 29 : $136-145,2016$

2. Moon RJ, Harvey NC, Curtis EM, de Vries F, van Staa T and Cooper C: Ethnic and geographic variations in the epidemiology of childhood fractures in the United Kingdom. Bone 85: 9-14, 2016.

3. Hedström EM, Svensson O, Bergström U and Michno P Epidemiology of fractures in children and adolescents. Acta Orthop 81: 148-153, 2010.

4. Morris MWJ and Bell MJ: The socio-economical impact of paediatric fracture clinic appointments. Injury 37: 395-397, 2006

5. Chevalley T, Bonjour JP, van Rietbergen B, Rizzoli R and Ferrari S: Fractures in healthy females followed from childhood to early adulthood are associated with later menarcheal age and with impaired bone microstructure at peak bone mass. J Clin Endocrinol Metab 97: 4174-4181, 2012.

6. He Z, Selvamurugan N, Warshaw J and Partridge NC: Pulsed electromagnetic fields inhibit human osteoclast formation and gene expression via osteoblasts. Bone 106: 194-203, 2018

7. Huang H, Zhao N, Xu X, Xu Y, Li S, Zhang J and Yang P: Dose-specific effects of tumor necrosis factor alpha on osteogenic differentiation of mesenchymal stem cells. Cell Prolif 44: 420-427, 2011.

8. Selwyn BM, Figueroa CD, Fink E, Swan A, Dieppe PA and Bhoola KD: A tissue kallikrein in the synovial fluid of patients with rheumatoid arthritis. Ann Rheum Dis 48: 128-133, 1989.

9. Lerner UH, Jones IL and Gustavsson GT: Bradykinin, a new potential mediator of inflammation-induced bone resorption: Studies of the effects on mouse calvarial bones and articular cartilage in vitro. Arthritis Rheum 30: 530-540, 1987.

10. Lerner UH and Lundberg P: Kinins and neuro-osteogenic factors. In: Bilezikian JP, Raisz LG, Rodan GA, (eds). Principles of bone biology. 2nd edition. San Diego, Academic Press, pp773-799, 2002

11. Lerner UH: Bradykinin synergistically potentiates interleukin-1 induced bone resorption and prostanoid biosynthesis in neonata mouse calvarial bones. Biochem Biophys Res Commun 175 775-783, 1991.

12. Teitelbaum SL and Ross FP: Genetic regulation of osteoclast development and function. Nat Rev Genet 4: 638-649, 2003.

13. Boyle WJ, Simonet WS and Lacey DL: Osteoclast differentiation and activation. Nature 423: 337-342, 2003.

14. Lerner UH: New molecules in the tumor necrosis factor ligand and receptor superfamilies with importance for physiological and pathological bone resorption. Crit Rev Oral Biol Med 15: 64-81, 2004.

15. Ghayor C, Correro RM, Lange K, Karfeld-Sulzer LS, Grätz KW and Weber FE: Inhibition of osteoclast differentiation and bone resorption by $\mathrm{N}$-methylpyrrolidone. J Biol Chem 286 24458-24466, 2011.

16. Miguel BS, Ghayor C, Ehrbar M, Jung RE, Zwahlen RA, Hortschansky P, Schmoekel HG and Weber FE: N-methyl pyrrolidone as a potent bone morphogenetic protein enhancer for bone tissue regeneration. Tissue Eng Part A 15: 2955-2963, 2009.

17. Ghayor C, Gjoksi B, Siegenthaler B and Weber FE: N-methyl pyrrolidone (NMP) inhibits lipopolysaccharide-induced inflammation by suppressing NF-kB signaling. Inflamm Res 64 $527-536,2015$.
18. Livak KJ and Schmittgen TD: Analysis of relative gene expression data using real-time quantitative PCR and the 2(-Delta Delta $\mathrm{C}(\mathrm{T}))$ method. Methods 25: 402-408, 2001.

19. Auer J, Berent B, Weber T and Eber B: Clinical significance of pleiotropic effects of statins: Lipid reduction and beyond. Curr Med Chem 9: 1831-1850, 2002.

20. Baud V and Karin M: Signal transduction by tumor necrosis factor and its relatives. Trends Cell Biol 11: 372-377, 2001.

21. Gaston MS and Simpson AH: Inhibition of fracture healing. J Bone Joint Surg Br 89: 1553-1560, 2007.

22. Bauer DC: HMG CoA reductase inhibitors and the skeleton: A comprehensive review. Osteoporos Int 14: 273-282, 2003

23. Bellosta S, Ferri N, Bernini F, Paoletti R and Corsini A: Non-liPid-related effects of statins. Ann Med 32: 164-176, 2000.

24. Casey PJ and Seabra MC: Protein prenyltransferases. J Biol Chem 271: 5289-5292, 1996.

25. Celeste AJ, Iannazzi JA, Taylor RC, Hewick RM, Rosen V, Wang EA and Wozney JM: Identification of transforming growth factor beta family members present in bone-inductive protein purified from bovine bone. Proc Natl Acad Sci USA 87: 9843-9847, 1990.

26. Chen G and Goeddel DV: TNF-R1 signaling: A beautiful pathway. Science 296: 1634-1635, 2002.

27. Hla T and Neilson K: Human cyclooxygenase- 2 cDNA. Proc Natl Acad Sci USA 89: 7384-7388, 1992.

28. Kurumbail RG, Kiefer JR and Marnett LJ: Cyclooxygenase enzymes: Catalysis and inhibition. Curr Opin Struct Biol 11: 752-760, 2001.

29. Knowles RG and Moncada S: Nitric oxide synthases in mammals. Biochem J 298: 249-258, 1994.

30. Calegari-Silva TC, Pereira RM, De-Melo LD, Saraiva EM, Soares DC, Bellio M and Lopes UG: NF-kappaB-mediated repression of iNOS expression in Leishmania amazonensis macrophage infection. Immunol Lett 127: 19-26, 2009.

31. Green SJ, Scheller LF, Marletta MA, Seguin MC, Klotz FW, Slayter M, Nelson BJ and Nacy CA: Nitric oxide: Cytokine-regulation of nitric oxide in host resistance to intracellular pathogens. Immunol Lett 43: 87-94, 1994.

32. Brechter AB and Lerner UH: Bradykinin potentiates cytokine-induced prostaglandin biosynthesis in osteoblasts by enhanced expression of cyclooxygenase 2 , resulting in increased RANKL expression. Arthritis Rheum 56: 910-923, 2007.

33. Zwipp Z, Hoffmann R, Thermann H and Wippermann BW: Rupture of the ankle ligaments. Int Orthop 15: 245-249, 1991

34. Stiell IG, Greenberg GH, McKnight RD, Nair RC, McDowell I and Worthington JR: A study to develop clinical decision rules for the use of radiography in acute ankle injuries. Ann Emerg Med 21: 384-390, 1992.

35. Stiell IG, McKnight RD, Greenberg GH, McDowell I, Nair RC, Wells GA, Johns C and Worthington JR: Implementation of the Ottawa ankle rules. JAMA 271: 827-832, 1994.

36. Stiell IG, Greenberg GH, McKnight RD, Nair RC, McDowell I, Reardon M, Stewart JP and Maloney J: Decision rules for the use of radiography in acute ankle injuries. Refinement and prospective validation. JAMA 269: 1127-1132, 1993.

37. Karpas A, Hennes H and Walsh-Kelly CM: Utilization of the Ottawa ankle rules by nurses in a pediatric emergency department. Acad Emerg Med 9: 130-133, 2002. 